LIPOVETSKY. G. \& SERROY, J. A estetização do mundo: viver na era do capitalismo artista. São Paulo: Companhia das Letras, 2015.

\title{
RESENHA DO LIVRO: A ESTETIZAÇÃO DO MUNDO: VIVER NA ERA DO CAPITALISMO ARTISTA
}

\author{
Alhen Rubens Silveira Damasceno ${ }^{1}$
}

Diante de um cenário complexo de fluidez material, de borramento de fronteiras, de excessos de informações e de exposições midiáticas, os consumidores se tornaram cada vez mais exigentes e tal afirmação se aprofunda no que tange a relação entre os processos produtivos e suas experiências de consumo. O mercado, além do seu aspecto tangível da produção, tem se preocupado cada vez mais com o imaterial, com o imaginário, com o onírico que possa ampliar sensações agradáveis nas mentes dos consumidores. O simbólico, o sensível, o prazer hedonista criado pelo encantamento das marcas, pela experiência sinestésica, pelo design, pela beleza, pela aura de completude é revelador de um consumidor que procura, antes de tudo, um encantamento estético diante de uma profusão de conteúdos. É nessa fruição estética, de ver o mundo pelos olhos do sensível, do provocativo e porque não do inusitado que o livro "A estetização do mundo: viver na era do capitalismo artista" dos autores Lipovetsky e Serroy vem discutir como o mercado e a arte estão em um processo de comum acordo para a produção e difusão de produtos estéticos que canalizem não só o prazer estético e experiencial do consumidor como também do lucro para as empresas.

Estruturado em seis capítulos, o livro vai relevando as nuanças em que a contemporaneidade ou, como chamam os autores do livro, a hipermodernidade vem se encaminhando. Na parte introdutória do livro, os autores nos inserem num campo em que o capitalismo é tido como um sistema sócio-econômico que enfeia o mundo. Ele, o capitalismo, homogeneíza as cidades com seus arranha-céus, comércios sempre ligados ao lucro, a população na era da mobilidade, egoísmo e um esvaziamento sentimental. Mas a pergunta que fica: Será que o sistema capitalista realmente "enfeia" o mundo? A reposta dessa pergunta provocativa permeia todo o livro no sentido de que o capitalismo

\footnotetext{
${ }^{1}$ Doutorando em Ciências da Comunicação pela Escola de Comunicações e Artes da Universidade de São Paulo sob a orientação da $\operatorname{Prof}^{a} \operatorname{Dr}^{a}$ Clotilde Perez, bolsita CAPES, membro do Grupo de pesquisa GESC3: Grupo de Estudos Semióticos em Comunicação, Cultura e Consumo. E-mail: alhenrubens@gmail.com
} 
na sua forma artista, transestética tem por finalidade unir arte, mercado, moda, publicidade, arquitetura, design, show business num grande mosaico, numa colcha de retalhos que não se trabalha na separação, divisão e sim nas sobreposições, nos cruzamentos, nas trocas criativas, nos afetos, no sensível, no embelezamento.

Os autores dividem a estetização do mundo em quatro períodos no decorrer da história da humanidade: a primeira vem a ser "a estetização ritual”, ou seja, uma era em que as convenções estéticas estão interligadas por meio do religioso, do mito, do mágico. As estruturas sociais e religiosas são as que ditam as regras estéticas, aqui não existe uma invenção de códigos, o fazer aqui é obedecer aos cânones existentes. Já na segunda era "a estetização aristocrática" que tem o momento histórico a Idade Média até o século XVIII, o grande salto que vemos é a emancipação do artista frente aos ensinamentos religiosos, aqui o artista procura atingir a perfeição em suas obras, o que há de mais belo e harmonioso e isso implica o estudo de técnicas mais elaboradas de confecção artística, uma arte voltada para exaltar a aristocracia.

Na terceira era "a moderna estetização do mundo" situada numa época em que o capitalismo já desponta como sendo o principal sistema econômico do mundo ocidental (século XVIII e XIX), os artistas estão mais livres para desenvolverem suas concepções artísticas do julgo da Igreja e da nobreza. Aqui se fala mais de uma "arte comercial" em que se adapta as demandas do público, uma arte opositiva entre as elites e as massas, do puro e do impuro, do comercial e do artístico. A quarta e última era da estetização do mundo vem a ser "a era transestética", ou melhor, o momento atual em que acabam-se as grandes oposições que predominava na era passada. O que cabe nessa nova era é a abundância, o cruzamento, as sobreposições, ou seja, as misturas entre a criação e o entretenimento, entre a arte e o show business, a comunicação, a moda. O importante nessa nova era são as sensações, as experiência sinestésicas, os prazeres.

No primeiro capítulo intitulado "O capitalismo artista" Lipovetsky \& Serroy vão discutir as principais razões em que o mundo contemporâneo perpassa e como o capitalismo artista se insere nessa nova etapa do modelo socioeconômico. Para os autores, uma boa definição de capitalismo artista vem da miscelânea de vários mercados, da hibridização de conceitos, das remixagens culturais, ou seja,

O capitalismo artista tem de característico o fato de que cria valor econômico por meio do valor estético e experimental: ele se afirma como um sistema conceptor, produtor e distribuidor de prazeres, de sensações, de encantamento. Em troca, uma das funções tradicionais da arte é assumida pelo universo empresarial. O capitalismo se tornou 
artista por estar sistematicamente empenhando em operações que, apelando para os estilos, as imagens o divertimento, mobilizam os afetos, os prazeres estéticos, lúdicos e sensiveis dos consumidores. O capitalismo artista é a formação que liga o econômico à sensibilidade e ao imaginário; ele se baseia na interconexão do cálculo e do intuitivo, do racional e do emocional, do financeiro e do artístico (2015:43).

Diante desse cenário de constante fruição estética entre o mercado e a produção artística, o olhar do sensível se torna mais aguçado no que tange a economia e a produção em massa, muito mais que meros produtos, hoje, o capitalismo artista se revela mais preocupado com a parte da experiência, do afetivo, do simbólico que o produto pode proporcionar ao seu consumidor.

Os autores dividem o capitalismo artista em três fases: a primeira fase tem como período o primeiro século do capitalismo de consumo até a II Grande Guerra Mundial. Essa fase se caracteriza pela criação das lojas de departamento, da publicidade, da moda de alta costura, do cinema, um capitalismo artista restrito aos centros urbano. Já a segunda fase entre os anos de 1950 a 1980 se caracteriza como um capitalismo artista estendido, ou seja, a lógica artística ganha em poder econômico e se difunde no design, na moda, nas indústrias culturais e a terceira fase vem da década de 1980 até os dias atuais. Uma dimensão transestética, ou seja, a hibridização em que há o cruzamento da indústria com a moda, com o design, com o comércio, a publicidade, o hiperconsumo é agora em escala mundial.

São com essas lógicas das fases do capitalismo artista que os capítulos dois e três vai se aprofundar. O capítulo dois “As figuras inaugurais do capitalismo artista” vai trabalhar com as fases um e dois, ou seja, com o nascimento do consumo moderno por meio das lojas de departamento e sua evolução para os templos do consumo atual, os shoppings centers; do surgimento e importância do cinema; da alta costura; do design funcionalista para o mercado; da publicidade do cartaz a grandes campanhas midiáticas.

O capítulo três "Um mundo design" vai se aprofundar na fase três do capitalismo artista. Nessa nova fase, os autores falam que o artista reaparece sob o signo midiático do criador estrelificado. Para eles "essa nova paisagem em que os territórios ficam indistintos, em que se esfumaçam as fronteiras entre arte e design, mas também entre arte e publicidade, arte e moda?" (20015:241). O capitalismo transestético é hibrido e isso fica mais evidente na forma como ele se afirma por meio de sobreposições, de interpretações, de transversalidades. Um design universal, multidimensional, emocional que transborda as qualidades do sensível e toca o consumidor por meio do contato com os sentimentos, com os seus gostos variados e com suas fantasias. 
A quarta parte do livro intitulado "O império do espetáculo e do divertimento", será dedicada ao mundo das indústrias criativas. Como os próprios autores alertaram no capítulo, aqui o importante não é a critica sobre o que é indústria criativa, mas como ela transforma o mundo das imagens, extrapola as experiências sensoriais, estimula o divertimento. Os autores explicitam que nessa nova cultura da espetacularização, de imagens, de comunicação, de lazer se situa:

É uma hipercultura midiático-mercantil, que se constrói não apenas com as indústrias do cinema, da música ou da televisão, mas também com a publicidade, a moda, a arquitetura, o turismo. Uma cultura que tem como característica implantar-se sob o signo hiperbólico da sedução, do espetáculo, da diversão de massa (2015: 236).

O penúltimo capítulo "O estágio estético do consumo" vem a aprofundar a questão do consumo dos indivíduos na relação consigo próprios e também na relação com o qual eles estabelecem com a cidade que os cerca. Uma vez saciada questão das necessidades básicas, o consumidor de agora "é cada vez mais comandado pela busca de emoções, pela exigência de se proporcionar "pequenos prazeres, pelo desejo de viver experiências agradáveis, de fruir bens de qualidade sensitiva, simbólica e estética" (2015:329). E muitos desses pequenos prazeres estão, como falam os autores, centrados nas atividades "não produtivas" em que as cidades estão amplamente se tornando especialistas, ou seja, lugares mais ligados ao lúdico, ao cultural com bares temáticos, restaurantes de chefs estrelas, reurbanizações de centros históricos para atraírem mais consumidores, festas em galpões, casarões antigos estilizados, museus e parques temáticos. Hoje em dia, os espaços urbanos são reinventados, reinterpretados em uma lógica que sirva de elo entre o comércio consumista e a estética mercantil apregoada pelo momento transestético do capitalismo artista.

O sexto e último capítulo "A sociedade transestética: até onde?" tem como finalidade recapitular todos os apontamentos da sociedade transestética que o livro muito bem pontuou ao longo dos cinco capítulos e também apontar para as contradições de se viver num momento em que a prática hedonista está hipercultuada dentro da sociedade e que ela se esbarra muitas vezes em questões éticas centrais tais como: saúde, educação, meio ambiente, trabalho, o desemprego. Assim sendo, o capitalismo artista tem como escopo social uma modificação nos modos relacionais entre o mercado e a arte, entre as pessoas e seus processos de identificação, usufruto dos espaços 
urbanos, fruição das benesses que o estético proporciona tanto no material quanto no experiencial.

Assim o capitalismo artista não só criou uma economia estética, mas pôs em movimento uma sociedade, uma cultura, um indivíduo estético de um gênero inédito. A estética se tornou um objeto de consumo de massa ao mesmo tempo que um modo de vida democrático. Isso para o bem e para o mal. O bem está no universo cotidiano cada vez. mais remodelado pela operatividade das artes, pela abertura de todos os prazeres do belo e das narrações emocionais; o mal, numa cultura degradada em show comercial sem consciência, numa vida fagocitada por um consumismo hipertrofiado (2015: 42122).

O livro "A estetização do mundo: viver na era do capitalismo artista" dos autores Lipovetsky \& Serroy no brinda com um instigante livro acerca as sociedade hipermoderna e como a arte e a estética vem influenciando o mercado contemporâneo. Como os setores criativos vem modificando o olhar do consumidor em relação ao belo, ao prazer, ao sonho por meio da estética que, somada com o mercado, impõe um novo significado de experiências que temos com o mundo que nos cerca.

Gilles Lipovetsky, filósofo francês e professor da Universidade de Grenoble, na França, é autor de inúmeros livros como: "A era do vazio", "O império do efêmero", A felicidade paradoxal", dentre outros. Uma de suas contribuições para o campo filosófico é o conceito de Hipermodernidade em que o prefixo "hiper" acompanhado do termo modernidade tem como significado a exacerbação de valores, a superabundância de produções e do seu consumo, o individualismo, as práticas culturais. Jean Serroy, professor da Universidade de Grenoble, é parceiro de Lipovestsky em várias publicações conjuntas sobre a sociedade contemporânea, ou como eles próprios utilizam, a sociedade hipermoderna.

\section{REFERÊNCIAS BIBLIOGRÁFICAS}

LIPOVETSKY. G. \& SERROY, J. A estetização do mundo: viver na era do capitalismo artista. São Paulo: Companhia das Letras, 2015.

Artigo submetido: 21/02/2015

Artigo aprovado: 13/04/2015 